
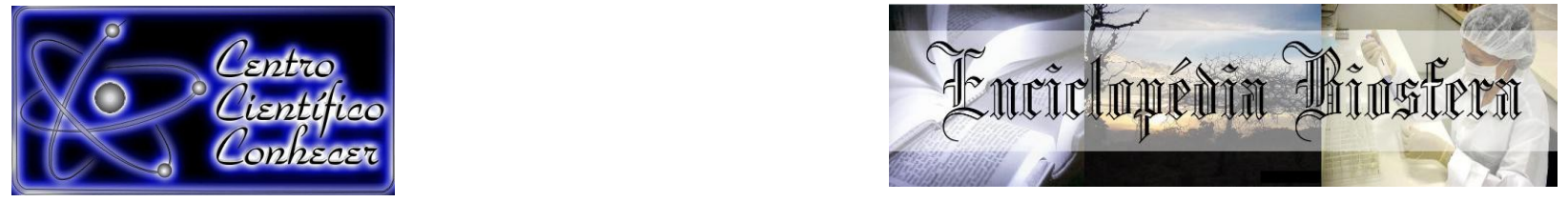

\title{
CRESCIMENTO INICIAL DE ESPÉCIES FRUTÍFERAS DO CERRADO EM ÁREA DEGRADADA PELA MINERAÇÃO EM JATAI-GO
}

Pedro Henrique Machado Vilela1, Wendy Carniello Ferreira ${ }^{2}$, Danielle Fabíola Pereira da Silva ${ }^{2}$

1 Aluno do curso de graduação em Engenharia Florestal. Universidade Federal de Goiás - Regional Jataí, Jataí, Goiás, Brasil.

2 Professores da Unidade Acadêmica Especial de Ciências Agrárias. Universidade

Federal de Goiás - Regional Jataí, Jataí, Goiás, Brasil. e-mail:

wcferreira_4@hotmail.com

Recebido em: 06/04/2018 - Aprovado em: 10/06/2018 - Publicado em: 20/06/2018

DOI: 10.18677/EnciBio_2018A31

\begin{abstract}
Este trabalho avaliou o crescimento de três espécies frutíferas nativas do cerrado em quatro diferentes doses de cama de frango, em uma área degradada pela mineração de cascalho em Jataí - GO. As mudas foram plantadas em quatro tratamentos, sendo um de cada dose. O plantio foi realizado em 15 de outubro de 2016 e foi avaliado de dezembro de 2016 até dezembro de 2017. As variáveis mensuradas foram a altura e o diâmetro das mudas a uma altura de cinco centímetros. Os resultados indicaram que até o décimo terceiro mês de avaliação as doses não influenciaram significativamente no incremento em altura e diâmetro das plantas. Porém, as espécies responderam de forma diferenciada entre elas e todas mostraram potencial para serem utilizadas no plantio em áreas degradadas pela mineração de cascalho. Desta forma, pode-se concluir que não é possível estabelecer qual a melhor dose para uma floresta mista avaliando-se um período de 13 meses.
\end{abstract}

RESUMO

PALAVRAS-CHAVE: Cama de frango, mineração, recuperação.

\section{INITIAL GROWTH OF FRUIT SPECIES OF CERRADO IN A DEGRADED AREA BY MINING IN JATAI, STATE OF GOIÁS, BRAZIL}

\begin{abstract}
This study evaluated the growth of three fruit species native to cerrado in four different doses of chicken, in a degraded area by gravel mining in Jataí-GO. The seedlings were planted in four blocks, one for each dose. The planting was held on 15 October 2016 and December 2016 was evaluated by December 2017, which measured the heights and diameters of seedlings at a height of $5 \mathrm{~cm}$. The results indicated that until the thirteenth month of the assessment did not influence significantly the increment in height and diameter of the planting. However, the species responded differently between them and all have shown the potential to be used in planting in areas degraded by mining of gravel. In this way, we can conclude that it is not possible to establish what the best dose for a mixed forest by evaluating a period of 13 months.
\end{abstract}

KEYWORDS: Land reclamation, mining, poultry litter. 


\section{INTRODUÇÃO}

São inúmeros os recursos fornecidos pelas formações vegetais do bioma Cerrado, tais como: frutos, sementes, cascas de árvores, raízes, folhas, óleos. Esses produtos florestais não madeireiros têm a extração e uso largamente praticados pelas populações rurais mais tradicionais, sendo importantes fontes de nutrientes e/ou renda (BARBOSA-SILVA et al., 2016). No entanto, há ainda necessidade de estudos profundos mostrando a utilidade das plantas de forma mais ampla. Estes estudos podem incentivar o uso e o manejo adequados, visando a valorização desses recursos e combatendo o extrativismo predatório, gerando assim diretrizes e políticas públicas efetivas para a conservação do Cerrado (FERREIRA et al., 2016).

Desta forma, a expressiva diversidade de espécies de valor alimentício, aliada a crescente tendência de procura e consumo dessas frutas nativas do Cerrado, pode constituir um nicho de exploração econômica, voltada para o aproveitamento desses recursos naturais, podendo também promover estímulo ao ecoturismo regional (PEREIRA; SANTOS, 2015).

O plantio de espécies nativas frutíferas é um modelo interessante para proporcionar alimento e atração da fauna silvestre. A formação de pomares de espécies frutíferas para fauna silvestre e para o consumo humano permite fornecimento de uma boa fonte de alimentos. Este modelo pode ser aplicado em áreas próximas a fragmentos florestais, onde pode fomentar a migração de animais da área florestal para a área em recuperação. Esta migração pode trazer propágulos da floresta original para a área florestal em recuperação (REIS et al., 2011).

No modelo supracitado, é possível utilizar espécies frutíferas nativas com capacidade de alimentar vários grupos de fauna (aves, morcegos, roedores etc.), desde que haja conectividade com fragmentos florestais nos quais existam estes grupos de animais (ALMEIDA, 2016).

Existe interesse no conhecimento do funcionamento dos ecossistemas florestais, sobretudo no que se refere à produtividade. Do ponto de vista ecológico, além da produtividade, é importante também a manutenção do equilíbrio em longo prazo, que depende em grande parte da ciclagem dos nutrientes. Esta, por sua vez, depende da adição e decomposição dos restos vegetais e animais e da atuação dos organismos presentes no solo (SILVA et al., 2015). Como o aumento da produção de aves na região Centro-Oeste do Brasil tem produzido um considerável montante de esterco animal para produção em potencial de adubos orgânicos (TROLEIS et al., 2017), a cama de frango tem potencial na recuperação de ecossistemas florestais. Diante do exposto, objetivou-se com este trabalho avaliar o comportamento de três espécies frutíferas nativas do Bioma Cerrado, em diferentes doses de cama de frango na recuperação de área degrada pela mineração de cascalho.

\section{MATERIAL E MÉTODOS}

O presente estudo foi realizado em uma cascalheira atualmente abandonada no município de Jataí, Goiás, dentro da área da Universidade Federal de Goiás Regional Jataí, no Campus Jatobá, nas coordenadas $17^{\circ} 52^{\prime} 53^{\prime \prime}$ de latitude sul e $51^{\circ}$ 42' 52" de longitude oeste, a 708 metros de altitude em relação ao nível do mar.

As atividades de extração de cascalho na referida área iniciaram-se no ano de 2015, com o intuito de suprir a demanda por cascalho para construção das vias pavimentadas da Universidade Federal de Goiás - Regional Jataí, segundo informações de colaboradores da universidade. 
O tipo de solo predominante na área é o Latossolo Vermelho-Escuro distroférrico (LRd), apresentando textura muito argilosa e argilosa, oriundos do basalto da formação Serra Geral, sendo profundos, muito porosos e permeáveis, com baixa suscetibilidade a erosão (SCOPEL; SILVA, 2001). A vegetação primitiva da área em estudo foi considerada como transição entre Floresta Estacional Semidecidual e Cerrado, se apresentando, amplamente fragmentada e em diversos estádios de sucessão (OLIVEIRA et al., 2015).

No preparo da área para o plantio, primeiramente foram feitas seis gradagens em área total, posteriormente foram abertos sulcos nas futuras linhas de plantio. Estes procedimentos foram realizados devido a área experimental apresentar extremamente pedregosa e compactada. Portanto, estas medidas objetivaram facilitar o desenvolvimento das raízes, sabendo que certamente as raízes ultrapassariam o volume do substrato presente nas covas, abertas com perfuratriz, com aproximadamente 27 litros (0,3 $\mathrm{m} \times 0,3 \mathrm{~m} \times 0,3 \mathrm{~m})$. O "top soil", que é a camada superficial do solo fundamental para recuperação de áreas degradadas pós mineração (LARA et al., 2017), não retornou a área minerada pois, foi perdido durante as operações de lavra.

Para o plantio foram utilizadas três espécies arbóreas frutíferas que ocorrem naturalmente em fitofisionomias do bioma Cerrado, sendo estas: jenipapo (Genipa americana), jatobá-do-cerrado (Hymenaea stigonocarpa) e ingá-cipó (Inga edulis). As mudas utilizadas neste trabalho foram doadas pelo Grupo Cosan e pela Secretaria Municipal de Meio Ambiente de Jataí, GO.

Desta forma, no dia 15 de outubro de 2016, as mudas foram plantadas em um espaçamento de 2,0 m x 1,0 m, com uma densidade de 5.000 plantas/ha (Figura 1), totalizando quatro tratamentos. Dentro de cada tratamento, foram distribuídas 15 mudas, contando com grupos de três indivíduos, sendo um de cada espécie com cinco repetições.

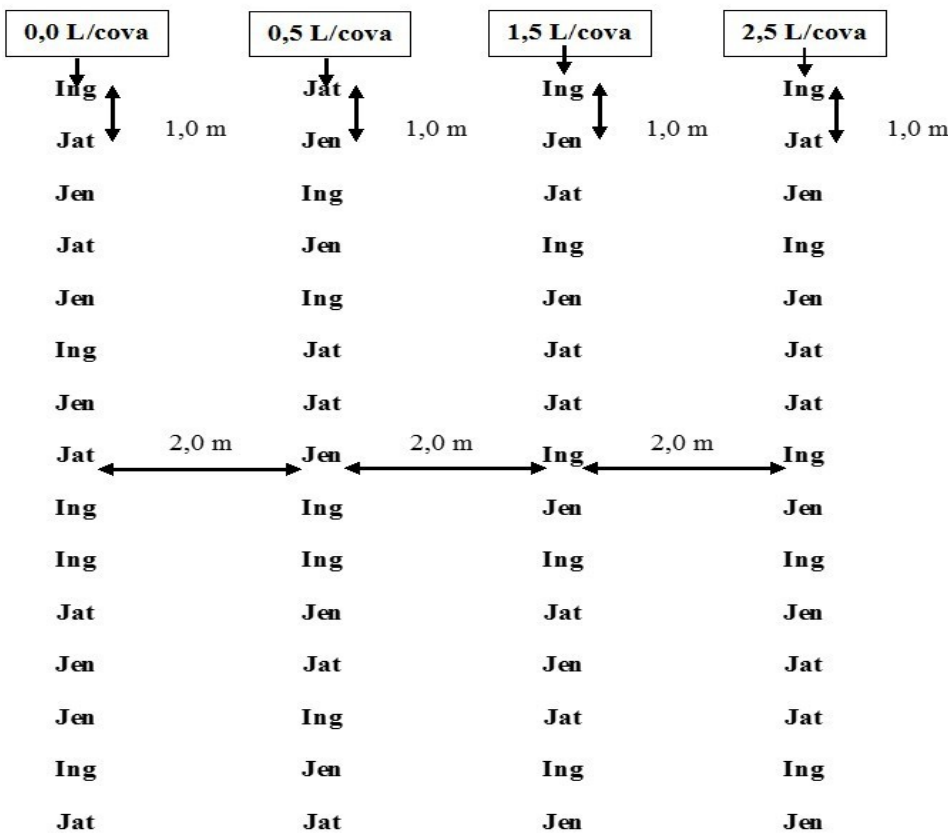

FIGURA 1. Croqui do plantio demonstrando disposição das espécies em campo bem como os espaçamentos utilizados em uma área degradada pela mineração em Jataí-GO. 
Dentro de cada linha, foram dispostas dosagens diferentes de matéria orgânica (Cama de frango) e a adubação química foi composta por $100 \mathrm{~g}$ de NPK 0525-15 por cova (Tabela 1 ).

TABELA 1. Tratamentos utilizados em função de doses de cama de frango em uma área degradada pela mineração em Jataí-GO.

\begin{tabular}{lcc}
\hline TRATAMENTOS & $\mathbf{N P K}(\mathbf{0 5 - 2 5 - 1 5 )}$ & CAMA DE FRANGO \\
& $(\mathbf{g})$ & $(\mathbf{L})$ \\
\hline $\mathbf{0 1}$ & 100 & 0,0 \\
$\mathbf{0 2}$ & 100 & 0,5 \\
$\mathbf{0 3}$ & 100 & 1,5 \\
$\mathbf{0 4}$ & 100 & 2,5 \\
\hline
\end{tabular}

Foram mensuradas, ao longo de 12 meses, as variáveis: sobrevivência, altura e diâmetro do caule das mudas plantadas. A altura das mudas foi mensurada medindo a distância da base do caule até a gema apical com a utilização de um bastão com uma fita métrica graduada em centímetros. $\mathrm{O}$ diâmetro foi medido com paquímetro digital da marca "Zaas precision" a cinco centímetros de altura, pois a área em questão é extremamente susceptível a erosões e, medir o diâmetro acima do nível do solo é uma precaução para que não se perca o ponto de medição ao longo do estudo. A altura do ponto de medição do diâmetro foi marcada com tinta no caule das plantas.

A primeira mensuração foi realizada 30 dias após o plantio, e as seguintes mensalmente, perfazendo um total de 13 medições. Também foi realizado o controle de formigas cortadeiras durante o período de avaliação utilizando como método de controle as iscas formicidas sempre que ataques as mudas eram notados, e realizadas capinas manuais sempre que necessário.

Para avaliar possíveis diferenças entre as médias dos tratamentos, aplicou-se - Teste $\mathrm{t}$, considerando o nível de significância de $5 \%(\mathrm{p}<0,05)$. As análises estatísticas foram realizadas com auxílio do software SPSS 20.0 ® for Windows (IMB SPSS, Armonk, New York, USA). O gráfico utilizado de precipitação mensal que está citado no presente trabalho é oriundo de dados da Estação Meteorológica de Jataí, localizada no Campus Jatobá, UFG REJ (INM, 2018).

O incremento periódico é o que a árvore cresceu em média em um determinado período de anos ou meses. O cálculo se baseia na diferença nos valores do início e fim do período de medição, visando eliminar a influência do porte inicial das plantas.

\section{RESULTADOS E DISCUSSÃO}

\section{Efeito das doses de cama de frango sobre o crescimento das espécies frutíferas nativas do cerrado}

Para crescimento em altura e diâmetro das três espécies estudadas não houve diferença estatística para o uso de diferentes doses de cama de frango (Tabelas 2 a 5). A necessidade de utilização de substratos naturais, tais como cama de frango, decorre do fato de que solos de áreas degradadas possuem baixos teores de matéria orgânica, consequentemente não são capazes de fornecer todos os nutrientes que as plantas precisam para um adequado crescimento e estabelecimento no local. Sendo assim, a cama de frango é capaz de suprir estes 
nutrientes. De acordo com relatos de Goulart et al. (2015), o uso de resíduos orgânicos pode tornar-se prática útil para os produtores, contribuindo para melhorar a fertilidade e conservação do solo e maior aproveitamento dos recursos existentes na propriedade.

O uso de cama de frango em diferentes doses visou avaliar como as espécies utilizadas responderiam ao longo do período experimental às necessidades nutricionais e a eficiência da cama de frango em recuperação de áreas degradadas (RAD), e desta forma confirmar que a utilização da cama de frango pode ser uma boa opção de adubação na implantação de espécies nativas do cerrado, pois, de acordo com Reatto et al. (2002), os solos do cerrado apresentam acidez elevada, e consequentemente baixa fertilidade. Com isso, são necessárias ações como, correção da acidez do solo antes do plantio, bem como a adubação para o melhor desenvolvimento das espécies.

A cama de frango, quando utilizada de forma correta, em dosagens apropriadas, gera benefícios que se expressam no plantio. Por outro lado, em dosagens exageradas, pode ser tóxica às plantas, ocasionando perda de produtividade. No presente estudo, devido às dosagens pequenas de cama de frango, não foram observadas diferenças estatísticas entre as doses. Segundo Costa et al. (2008), a cama de frango, desde que utilizada em quantidades adequadas, no modo ideal de preparo e na composição certa com outros substratos para as diferentes culturas, pode ser uma fonte de nutrientes interessante para ser aproveitada tanto na produção de mudas, quanto na adubação em geral.

- Inga edulis

O Inga edulis, apesar de ser uma espécie que tem preferência por áreas alagadas, apresentou um desenvolvimento razoável na área degradada do estudo. Durante as avaliações, foi uma espécie que mostrou alguns indicadores biológicos, como simbiose com formigas, o que pode indicar recuperação satisfatória da área, assim como, por ser uma leguminosa, é uma espécie fixadora de nitrogênio no solo, tem associações com fungos micorrizos, produz serapilheira de boa qualidade, o que proporciona ambiente ideal para estabelecimento e desenvolvimento da regeneração natural (JUSTINO et al., 2017). O potencial de reabilitação de áreas alteradas com algumas espécies arbóreas, principalmente leguminosas arbóreas, nodulíferas e de crescimento rápido, entre estas Inga edulis, é fundamental para o estabelecimento sustentável e de baixo aporte de insumos de reflorestamento de espécies nativas (RANGEL-VASCONCELOS et al., 2016).

As doses de cama de frango variando de 0,5 até $2,5 \mathrm{~L}$ por cova não surtiram efeitos significativos sobre o crescimento inicial das plantas (Tabela 2). Desta forma, não foi possível diferenciar qual a melhor dose para a espécie em estudo. Em estudos para avaliar o efeito de doses de cama de aves e tempos de incubação, no desenvolvimento inicial de plantas de milho, Silva et al. (2011) verificaram que o suprimento de 10,5 gramas de cama de frango por quilo de solo, o equivalente a $15,8 \mathrm{t} \mathrm{ha}^{-1}$, incubadas por 30 dias, promoveram maior altura de plantas e massa seca de folhas e colmos de milho.

As mudas utilizadas no presente trabalho, devido ao longo período de exposição em viveiro antes da implantação das mesmas no campo, apresentaram sistema radicular comprometido no momento do plantio, o que influenciou negativamente no crescimento inicial e mortalidade das mesmas. Outro fator que influenciou o crescimento de forma negativa foi o ataque de formigas cortadeiras. 
Nas doses de 0,0 e 2,5 da cama de frango, observou-se crescimento médio mensal em torno de $4,0 \mathrm{~cm} / \mathrm{mês}$. De acordo com relatos de Lima (2016), espécies que apresentam incremento em altura superior a $40 \mathrm{~cm} /$ ano apresentam potencial para recuperação de áreas, o que seria equivalente a $3,3 \mathrm{~cm} / \mathrm{mês}$. Esta afirmação demonstra o potencial de Inga edulis na recuperação de áreas degradadas.

TABELA 2. Incremento em altura e diâmetro nas diferentes doses utilizadas para Inga edulis em função de doses de cama de frango em uma área degradada pela mineração em Jataí-GO durante 13 meses de avaliação

\begin{tabular}{|c|c|c|}
\hline & DOSE(L/cova) & MÉDIAS \\
\hline $\mathrm{IPH}(\mathrm{cm})$ & 0,0 & $61,6667 a$ \\
\hline IPH (cm) & 0,5 & $31,0000 a$ \\
\hline $\mathrm{IP} \varnothing(\mathrm{mm})$ & 0,0 & $16,3267 a$ \\
\hline $\mathrm{IP} \varnothing(\mathrm{mm})$ & 0,5 & $11,4950 a$ \\
\hline $\mathrm{IPH}(\mathrm{cm})$ & 0,0 & $61,6667 a$ \\
\hline IPH (cm) & 1,5 & $29,6667 a$ \\
\hline $\mathrm{IP} \varnothing(\mathrm{mm})$ & 0,0 & $16,3267 a$ \\
\hline $\mathrm{IP} \varnothing(\mathrm{mm})$ & 1,5 & $10,2500 a$ \\
\hline $\mathrm{IPH}(\mathrm{cm})$ & 0,0 & $61,6667 a$ \\
\hline IPH (cm) & 2,5 & $63,6667 a$ \\
\hline $\mathrm{IP} \varnothing(\mathrm{mm})$ & 0,0 & $16,3267 a$ \\
\hline $\mathrm{IP} \varnothing(\mathrm{mm})$ & 2,5 & $13,9533 a$ \\
\hline
\end{tabular}

$\mathrm{a}=$ não diferem entre si, pelo Teste de $\mathrm{t}(5 \%) . \quad \mathrm{IPH}=$ Incremento periódico em altura. $\mathrm{IP} \varnothing=$ Incremento periódico do diâmetro.

- Hymenaea stigonocarpa

Observou-se crescimento em altura e diâmetro superior na dose 0,0 (testemunha), apesar de não significativo (Tabela 3). O jatobá-do-cerrado caracteriza-se como espécie típica de solos ácidos, e pouco exigente em nutrientes para o seu desenvolvimento, apesar de ter o crescimento lento. Segundo Carvalho (2007), Hymenaea stigonocarpa ocorre, naturalmente, em solos secos e, em solos de fertilidade baixa, mas sempre em terrenos bem drenados. Portanto, H.stignocarpa pode ser indiferente à adubação, por se tratar de uma espécie típica de formações savânicas (FINGER; FINGER, 2015).

Torres et al. (2011), testando diferentes doses de cama de frango não curtida, na germinação e crescimento de mudas de pinhão manso, observaram efeito decrescente na altura, diâmetro do caule, área foliar e número de folhas a partir da dose de $10 \%$. Isso pode ter ocorrido pelo fato da cama de frango utilizada não ter passado pelo processo de decomposição antes da implantação do experimento. Um dos fatores que afetou o desenvolvimento das plantas é que o aumento da quantidade de bactérias que fazem o processo de decomposição da cama de frango no substrato diminui a quantidade de oxigênio e imobiliza o nitrogênio disponível por um período.

Apesar da importância da espécie, ainda existem poucos estudos que discorrem a respeito do jatobá-do-cerrado, principalmente em relação à adubação e a produção de mudas, fato este que pode estar associado a maior predominância da espécie no bioma Cerrado. Além disso, entre o pequeno número de estudos a respeito da espécie, existem muitas divergências em relação às necessidades nutricionais do jatobá-do-cerrado.

Independente da dose, estatisticamente não houve diferença no crescimento do jatobá-do-cerrado, mas este se mostrou adequado para recuperação de áreas degradadas, com valor de incremento em altura superior a $3,3 \mathrm{~cm} / \mathrm{mês}$ (LIMA, 2016). ENCICLOPÉDIA BIOSFERA, Centro Científico Conhecer - Goiânia, v.15 n.27; p.85 2018 
TABELA 3. Incremento em altura e diâmetro nas diferentes doses utilizadas para Hymenaea stigonocarpa em função de doses de cama de frango em uma área degradada pela mineração em Jataí-GO, durante 13 meses de avaliação

\begin{tabular}{ccc}
\hline & DOSE(L/cova) & MÉDIAS \\
\hline IPH $(\mathrm{cm})$ & 0,0 & $75,0000 \mathrm{a}$ \\
IPH (cm) & 0,5 & $60,0000 \mathrm{a}$ \\
IP $\varnothing(\mathrm{mm})$ & 0,0 & $15,7575 \mathrm{a}$ \\
IP $\varnothing(\mathrm{mm})$ & 0,5 & $14,5420 \mathrm{a}$ \\
\hline IPH (cm) & 0,0 & $75,0000 \mathrm{a}$ \\
IPH (cm) & 1,5 & $40,2000 \mathrm{a}$ \\
IP $\varnothing(\mathrm{mm})$ & 0,0 & $15,7575 \mathrm{a}$ \\
IP $\varnothing(\mathrm{mm})$ & 1,5 & $11,7080 \mathrm{a}$ \\
\hline IPH (cm) & 0,0 & $75,0000 \mathrm{a}$ \\
IPH (cm) & 2,5 & $51,4000 \mathrm{a}$ \\
IP $\varnothing(\mathrm{mm})$ & 0,0 & $15,7575 a$ \\
IP $\varnothing(\mathrm{mm})$ & 2,5 & $12,5800 \mathrm{a}$ \\
\hline
\end{tabular}

$\mathrm{a}=$ não diferem entre si, pelo Teste de $\mathrm{t}(5 \%) . \quad \mathrm{IPH}=$ Incremento periódico em altura. $\mathrm{IP} \varnothing=$ Incremento periódico do diâmetro.

- Genipa americana

Genipa americana apresenta alta plasticidade ecológica, ocorrendo em várias formações florestais, desenvolvendo-se em solos permeáveis, superficiais a moderadamente profundos e ácidos, preferindo terrenos úmidos, encharcados ou inundáveis (CARVALHO, 1994, CRUZ; CAMPOS, 2015). Diante disto, percebe-se que, apesar de ser uma espécie que tenha preferência por solos com maior disponibilidade de água, o jenipapo se adapta bem a vários outros tipos de solos. Observou-se que, apesar de não significativo, houve um maior incremento nos tratamentos com cama de frango (Tabela 4). Durante os períodos de estiagem, houve maior retenção de umidade pela matéria orgânica do solo.

O melhor desenvolvimento da espécie na presença da cama de frango é um indicativo que com maiores doses, pode-se melhorar o desenvolvimento da planta. Mas a espécie se mostrou apta para ser utilizada em recuperação de áreas degradadas, com a utilização de no mínimo 2,5 litros de cama de frango/cova, pelo fato de apresentar incremento em altura superior a 3,3 cm/mês (LIMA, 2016).

TABELA 4. Incremento em altura e diâmetro nas diferentes doses utilizadas para Genipa americana em função de doses de cama de frango em uma área degradada pela mineração em Jataí-GO, durante 13 meses de avaliação

\begin{tabular}{ccc}
\hline & DOSE(L/cova) & MÉDIAS \\
\hline IPH (cm) & 0,0 & $30,8000 \mathrm{a}$ \\
IPH (cm) & 0,5 & $38,8000 \mathrm{a}$ \\
IP $\varnothing(\mathrm{mm})$ & 0,0 & $16,9300 \mathrm{a}$ \\
IP $\varnothing(\mathrm{mm})$ & 0,5 & $18,8080 \mathrm{a}$ \\
\hline IPH (cm) & 0,0 & $30,8000 \mathrm{a}$ \\
IPH (cm) & 1,5 & $32,6000 \mathrm{a}$ \\
IP $\varnothing(\mathrm{mm})$ & 0,0 & $16,9300 \mathrm{a}$ \\
IP $\varnothing(\mathrm{mm})$ & 1,5 & $17,7800 \mathrm{a}$ \\
\hline IPH (cm) & 0,0 & $30,8000 \mathrm{a}$ \\
IPH (cm) & 2,5 & $48,5000 \mathrm{a}$ \\
IP $\varnothing(\mathrm{mm})$ & 0,0 & $16,9300 \mathrm{a}$ \\
IP $\varnothing(\mathrm{mm})$ & 2,5 & $16,4950 \mathrm{a}$ \\
\hline
\end{tabular}


$a=$ não diferem entre $\mathrm{si}$, pelo Teste de $\mathrm{t}(5 \%) . \quad \mathrm{IPH}=$ Incremento periódico em altura. $\mathrm{IP} \varnothing=$ Incremento periódico do diâmetro.

- Geral:

O efeito das doses não foi significativo quando foram avaliadas todas as espécies em estudo conjuntamente (Tabela 5). Desta forma, é possível afirmar que outros fatores interferem no crescimento das mudas, tais como a capacidade de adaptação no solo, preferência por tipos de solos e exigência hídrica.

TABELA 5. Incremento em altura e diâmetro nas diferentes doses utilizadas para média geral em função de doses de cama de frango em uma área degradada pela mineração em Jataí-GO, durante 13 meses de avaliação

\begin{tabular}{|c|c|c|}
\hline & DOSE(L/cova) & MÉDIAS \\
\hline $\mathrm{IPH}(\mathrm{cm})$ & 0,0 & $53,2500 a$ \\
\hline $\mathrm{IPH}(\mathrm{cm})$ & 0,5 & $46,3333 a$ \\
\hline $\operatorname{IP} \varnothing(\mathrm{mm})$ & 0,0 & $16,3883 a$ \\
\hline $\operatorname{IP} \varnothing(\mathrm{mm})$ & 0,5 & $15,8117 a$ \\
\hline $\mathrm{IPH}(\mathrm{cm})$ & 0,0 & $53,2500 a$ \\
\hline IPH $(\mathrm{cm})$ & 1,5 & $34,8462 a$ \\
\hline $\operatorname{IP} \varnothing(\mathrm{mm})$ & 0,0 & $16,3883 a$ \\
\hline $\operatorname{IP} \varnothing(\mathrm{mm})$ & 1,5 & $13,7069 a$ \\
\hline IPH (cm) & 0,0 & $\overline{53,2500 a}$ \\
\hline $\mathrm{IPH}(\mathrm{cm})$ & 2,5 & $53,5000 a$ \\
\hline $\mathrm{IP} \varnothing(\mathrm{mm})$ & 0,0 & $16,3883 a$ \\
\hline $\operatorname{IP} \varnothing(\mathrm{mm})$ & 2,5 & $14,2283 a$ \\
\hline
\end{tabular}

$a=$ não diferem entre si, pelo Teste de t $(5 \%) . \quad \mathrm{IPH}=$ Incremento periódico em altura. $\quad \mathrm{IP} \varnothing=$ Incremento periódico do diâmetro.

\section{Crescimento mensal das espécies avaliadas (Curvas de crescimento)}

Durante as 13 avaliações (Dez/2016 à Dez/2017), de modo geral, para todas as espécies em estudo, as curvas de crescimento em altura ficaram praticamente estáveis (horizontais) de maio a outubro. Observou-se que o crescimento em diâmetro diminuiu neste período (Tabelas 3 a 5). Este comportamento foi observado no período de baixa precipitação pluviométrica (Figura 2).

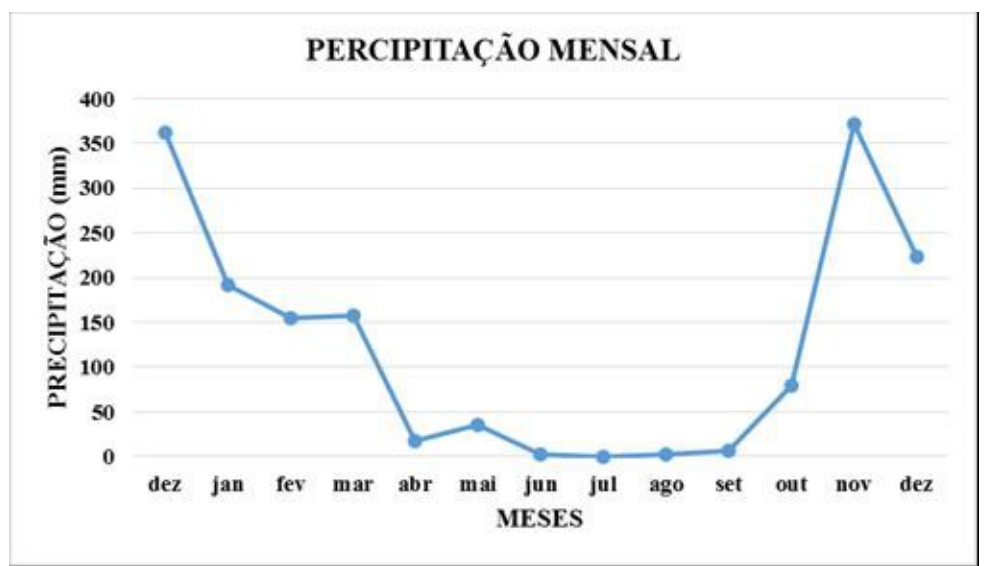

FIGURA 2. Gráfico da precipitação mensal do período de avaliação das espécies. Dados oriundos da Estação Meteorológica de Jataí, localizada no 
- Inga edulis

Campus Jatobá, UFG REJ (Fonte: INM, 2018).

Observa-se, na Figura 3, distanciamento entre as médias dos valores iniciais do diâmetro, pelo fato da ausência de padronização e vigor diferente entre as mudas, mesmo que dispostas aleatoriamente. Portanto, alguns tratamentos se constituíram de mudas com maior diâmetro inicial. Independentemente da dose, seguiram ritmo de crescimento mais lento entre os períodos dos meses de maio à setembro, devido ao período de estiagem.

Pode-se notar superioridade nos valores da dose 2,5 L/cova, que por apresentar maior teor de matéria orgânica, levou a maior retenção de umidade. Observou-se pico de crescimento após o mês de outubro, quando se inicia o período chuvoso.

Em relação à curva de crescimento em altura, houve maior variação em função do ataque de formigas cortadeiras e coleópteros que se alimentaram das gemas apicais. Observa-se, na Figura 3, no mês de agosto um decréscimo no ganho em altura, certamente devido aos ataques de formigas cortadeiras e coleópteros. Mas mesmo com todas essas injúrias, a espécie conseguiu recuperar o crescimento. Como o plantio não visa produção de madeira para serraria e sim recuperar a área com recobrimento do solo e produção de frutos, o corte das gemas apicais por formigas e coleópteros em baixa intensidade pode estimular o surgimento de gemas laterais, gerando aumento do volume de copa, o que é ideal para recuperação de áreas degradadas (DAVIDE; BOTELHO, 2015).

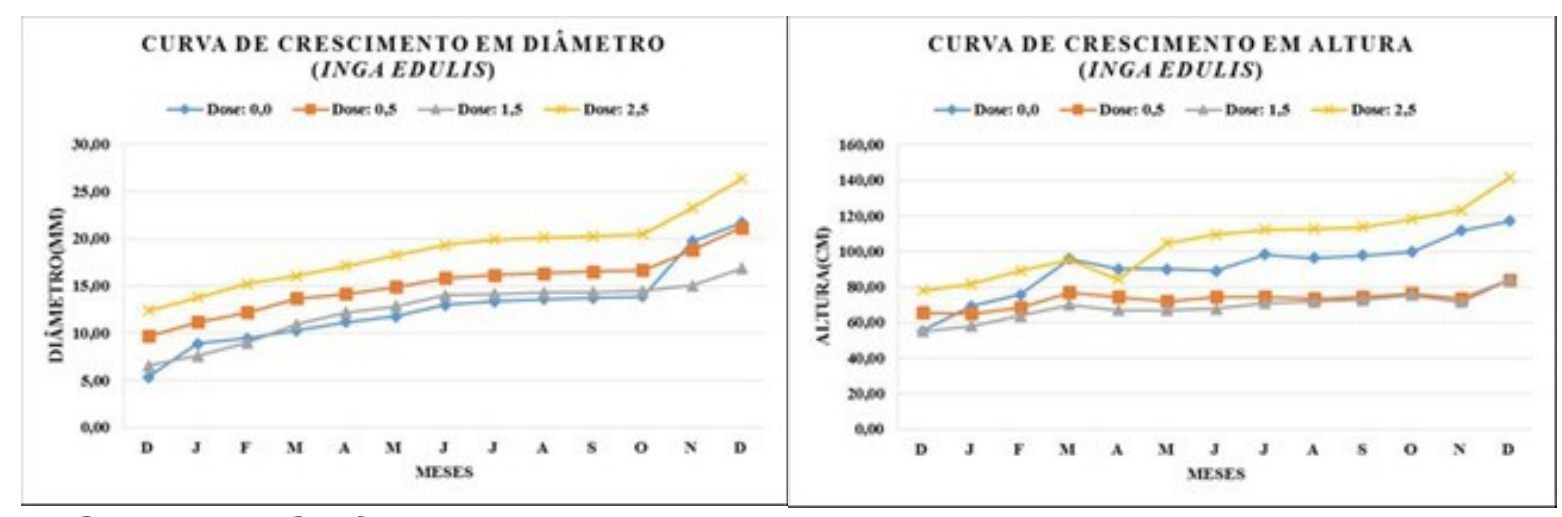

FIGURA 3. Gráfico de crescimento de Inga edulis ao longo do período de avaliação em área degradada pela mineração em Jataí-GO.

- Hymenaea stigonocarpa

Durante o período de medição, notou-se que o incremento em diâmetro desta espécie não foi influenciado pelas doses de cama de frango, sendo possível observar maior destaque para as menores doses de cama de frango (Figura 4). De acordo com relatos de Carvalho (2014), H. stignocarpa é encontrado naturalmente em solos secos e de fertilidade baixa, mas sempre em terrenos bem drenados.

Em relação ao crescimento em altura, o jatobá-do-cerrado é considerado uma espécie de crescimento lento por investir primeiramente no crescimento radicular. Plantas do Cerrado investem predominantemente em sistema radicular nos estágios iniciais de desenvolvimento, com uma razão raiz/parte aérea entre um a nove para plantas entre cinco a sete meses de vida (PAULILO; FELIPPE, 1998; MOREIRA; KLINK, 2000). Tempo mais longo para desenvolvimento da parte aérea foi 
compensada pelo fato da folhagem ser menos palatável pelos insetos, ou qualquer outro herbívoro.

As espécies frutíferas do cerrado reduzem de forma drástica o crescimento da parte aérea no período de estiagem, as atividades fisiológicas com a baixa disponibilidade de água praticamente cessam e mantêm o funcionamento apenas para a sobrevivência. Assim que retorna o período chuvoso, às mesmas são ativadas normalmente.
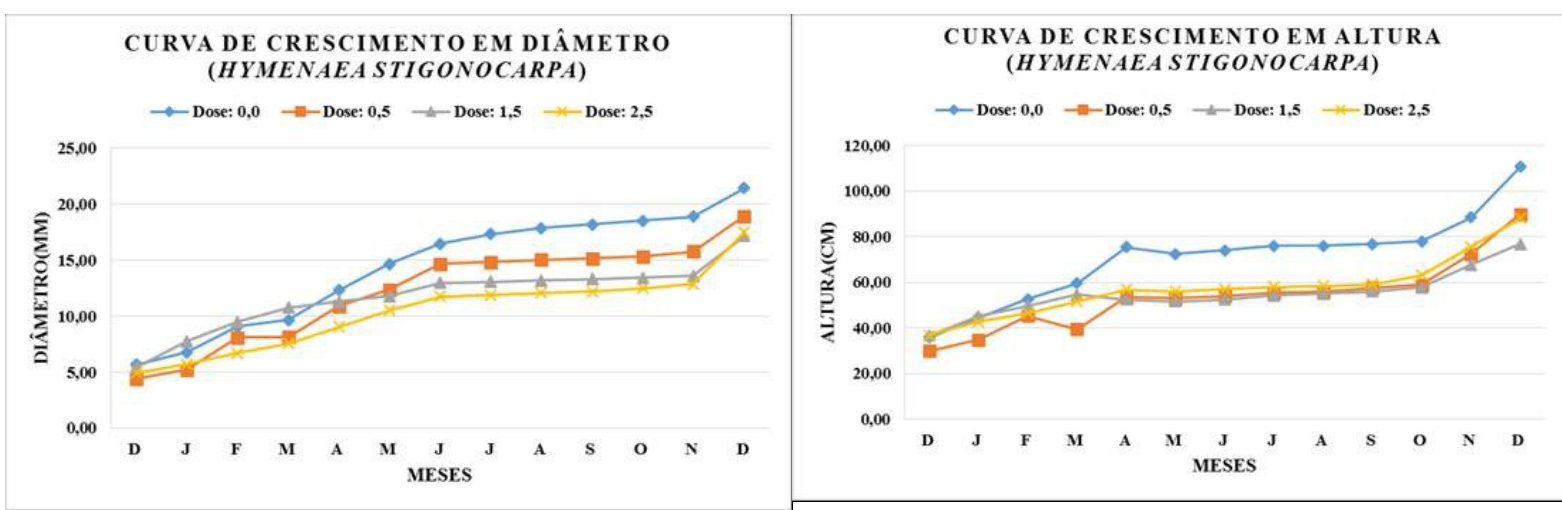

FIGURA 4. Gráfico de crescimento em diâmetro do Hymenaea stigonocarpa ao longo do período de avaliação em área degradada pela mineração em Jataí-GO.

\section{- Genipa americana}

Para o crescimento inicial tanto para diâmetro quanto para altura, observouse maiores ganhos quando utilizadas maiores doses de cama de frango. O intenso ataque de formigas cortadeiras observado ao longo de todo o período experimental, não permitiu que o crescimento inicial em altura não se igualasse no período chuvoso. De acordo com relatos de Carvalho (2003), em plantios experimentais, no Paraná, o jenipapeiro tem crescido mais vigorosamente em solos de fertilidade elevada, bem drenados e com textura de franca a argilosa. Trata-se de espécie rústica, pouco exigente quanto às propriedades físicas dos solos. Desenvolve-se em solos permeáveis, superficiais a moderadamente profundos e ácidos. Prefere terrenos úmidos, encharcados ou inundáveis.
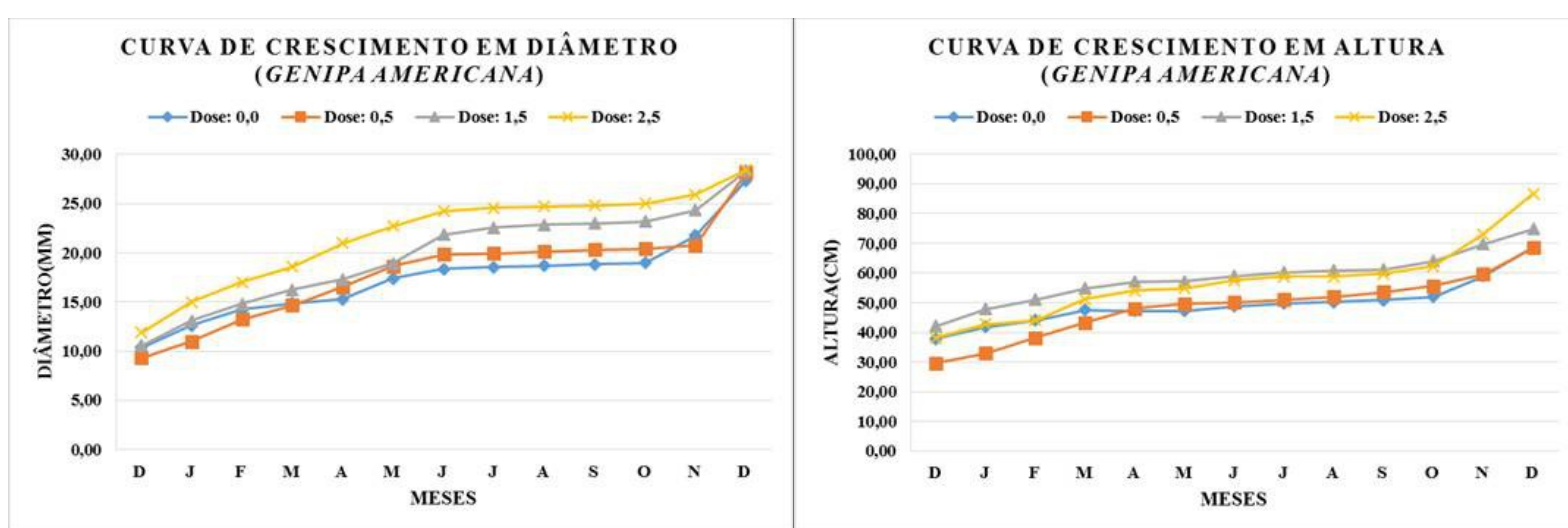

FIGURA 5. Gráfico de crescimento em diâmetro do Genipa americana ao longo do período de avaliação em área degradada pela mineração em Jataí-GO. 


\section{Comparação do crescimento entre as espécies frutíferas nativas plantadas}

As espécies Inga edulis e Hymenaea stigonocarpa apresentaram menores incrementos em diâmetro em relação a Genipa americana, devido ao fato de Inga edulis ser uma espécie que tem preferência por matas ciliares e margens de lagos, onde a disponibilidades de água é maior, e, por solos mais arenosos (Tabela 6). $\mathrm{Na}$ área de estudo, o solo encontra-se pedregoso e com baixa disponibilidade de água, portanto, nota-se que é uma espécie com dificuldade para adaptar em solos degradados. Hymenaea stigonocarpa teve crescimento inferior também em relação à Genipa americana pelo fato de características morfofisiológicas próprias como crescimento lento, folhas ásperas e maior investimento inicial de crescimento na parte radicular. Por outro lado, trata-se de espécie com maior resistência a solos mais secos e pedregosos, apresentando baixa taxa de mortalidade.

Observou-se que as espécies com menor incremento em diâmetro apresentaram maiores incrementos em altura. As plantas que se destacaram em altura foram as que sofreram menos com ataques de formigas e coleópteros, por possuírem folhas menos palatáveis e atrativas.

Genipa americana obteve maior incremento periódico médio em diâmetro em relação as demais espécies em estudo, por apresentar alta plasticidade ecológica e, Hymenaea stignocarpa, com maior incremento periódico médio em altura, por sofrer menor ataque de formigas cortadeiras (Tabela 6).

TABELA 6. Incremento periódico médio em altura e diâmetro, em função de doses de cama de frango em uma área degradada pela mineração em Jataí-GO.

\begin{tabular}{lcc}
\hline ESPÉCIES & IP $\varnothing \mathbf{M}(\mathbf{m m})$ & IPHM(cm) \\
\hline Inga edulis & 13,14 & 47,91 \\
Hymenaea stigonocarpa & 13,54 & 55,68 \\
Genipa americana & 17,56 & 37,11 \\
\hline IPøM = Incremento periódico do diâmetro médio. & IPHM = Incremento periódico em altura médio.
\end{tabular}

\section{Sobrevivência}

A taxa de sobrevivência das mudas após 13 meses de plantio foi de $81,67 \%$, num total de 60 plantas. De modo geral, a maioria dos trabalhos sobre recuperação de áreas degradadas indica que mortalidades de até $20 \%$ são consideradas normais em projetos de reflorestamento em áreas utilizadas para a exploração mineral. No entanto, Almeida e Sánchez (2005) consideram mortalidade de 10\% um valor de referência em seus projetos de reflorestamento em áreas mineradas. No estado de São Paulo, obtiveram um índice de sobrevivência de $62 \%$ do total de mudas plantadas. Desta forma, é possível considerar que após 13 meses, a sobrevivência das mudas do presente estudo se mostrou satisfatória.

A espécie que apresentou maior mortalidade foi Inga edulis, que apresentou $81,82 \%$ de todas as mudas mortas. O restante das mudas mortas foi das espécies Genipa americana e Hymenaea stigonocarpa, ambas com 9,09\%. Considerando apenas mudas plantadas da espécie Inga edulis, a sobrevivência foi de $55,0 \%$ (Figura 6). Pode-se afirmar que entre as espécies utilizadas, I. edulis foi a que mostrou maior dificuldade de se estabelecer em áreas mineradas. Alguns dos fatores que dificultaram o estabelecimento no local foram por ser uma espécie típica de matas ciliares e a idade das mudas bastante avançada, o que ocasionou o enovelamento das raízes, já que encontravam-se bastante enraizadas no solo do viveiro. Com isso, no momento do manejo das mudas, o sistema radicular foi danificado. 
Genipa americana apresenta alta plasticidade ecológica, ocorrendo em várias formações florestais de toda a América Tropical. Adapta-se bem a tipos variados de solo, mas tem preferência por solos areno-argilosos, permeáveis, profundos, bemdrenados com pH 6,0-6,5 (CARVALHO, 1994, CRUZ; CAMPOS, 2015). No entanto, a taxa de sobrevivência de $95 \%$ (Figura 6) mostrou-se satisfatória no presente estudo. O período de "veranico" que ocorreu logo após o plantio das mudas pode ter influenciado diretamente a taxa de sobrevivência nos primeiros meses de estudo.

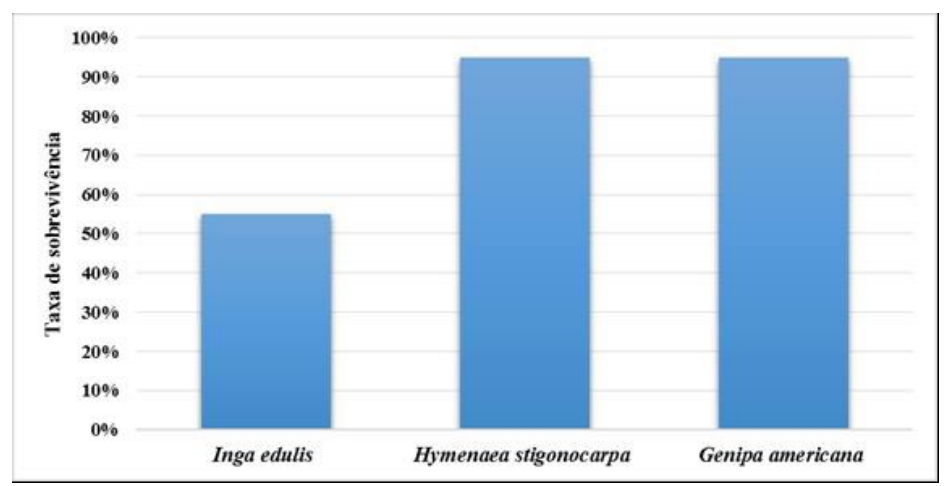

FIGURA 6. Gráfico de sobrevivência das mudas das espécies utilizadas após 13 meses em função de doses de cama de frango em área degradada pela mineração em Jataí-GO.

\section{CONCLUSÕES}

As três espécies conseguiram se estabelecer na área degradada pela mineração, com destaque para Genipa americana e Hymenaea stigonocarpa, que apresentaram taxas de sobrevivência superiores a $90 \%$. Todas as espécies em estudo demonstram potencial para serem utilizadas em áreas degradas pela mineração de cascalho.

Apesar de não haver diferenças significativas entre os tratamentos, a configuração gráfica das curvas de crescimento em diâmetro de colo e altura das plantas evidencia uma tendência de que a adição de cama de frango traz maiores incrementos nestas variáveis para as espécies Genipa americana e Inga edulis. Não foi possível determinar a melhor dose de cama de frango para reflorestamento misto em área degradada.

\section{REFERÊNCIAS}

ALMEIDA, D. S. Recuperação ambiental da Mata Atlântica [online].3rd ed. rev. and enl. Ilhéus, BA: Editus, 2016, 200 p. ISBN 978-85-7455-440-2. Disponível em: SciELO Books. <http://books.scielo.org>. doi: https://doi.org/10.7476/9788574554402.

ALMEIDA, R. O. P. O.; SANCHEZ, L. E. Revegetação de áreas de mineração: critérios de monitoramento e avaliação do desempenho. Revista Árvore, Viçosa, v. 29, n. 1, p. 47-54, 2005. Disponível em <http://www.scielo. br/scielo.php? script=sci_arttext\&pid=S010067622005000100006\&lng=pt\&nrm=iso>. acessos em 06 fev. 2018. http://dx.doi.org/10.1590/S0100-67622005000100006. 
BARBOSA-SILVA, D.; ROCHA, D. M. S.; FERREIRA, J. R. P.; FAGUNDES, G.L.; COSTA, F. M. P.; Produtividade de duas espécies frutíferas nativas do Cerrado. Cadernos de Agroecologia, v. 10, n. 3, 2016. ISSN 2236-7934. Disponível em: http://revistas.aba-agroecologia.org.br/index.php/cad/article/view/19913.

CARVALHO, P.E.R.; Espécies arbóreas brasileiras. Brasília, DF: Embrapa informações Tecnológica; Colombo, PR: Embrapa Florestas, 2014. 634 p. II color; (Coleção espécies Arbóreas, v.5).

CARVALHO, P. E. R.; Espécies florestais brasileiras: recomendações silviculturais, potencialidades e uso da madeira. Colombo: EMBRAPACNPF/ Brasília: EMBRAPA - SPI, 1994. 640p.

CARVALHO, P. E. R.; Jenipapeiro. Colombo: Embrapa Florestas. 2003. 14 p. (Circular Técnica, 80).

COSTA, L. C. B.; ROSAL, L. F.; PINTO, J. E. B. P.; BERTOLUCCI, S. K. V. Efeito da adubação química e orgânica na produção de biomassa e óleo essencial em capim limão Cymbopogon citratus (DC) Stapf. Revista Brasileira de Plantas Medicinais, Botucatu, v.10, n.1, p.16-20, 2008. Disponível em: http://www.sbpmed.org.br/download/issn_08_1/artigo3_v10_n1_p16a20.pdf

CRUZ, M. P.; CAMPOS, J. B.; Estrutura e composição do estrato herbáceo-arbustivo em duas áreas florestais com diferentes idades de recuperação, na Planície de Inundação do Alto Rio Paraná. Ambiência, Guarapuava (PR) v.11 n.2 p. 375 - 392 Jan./Abr. 2015 ISSN $1808 \quad$ - $0251 . \quad$ Disponível em: http://revistas.unicentro.br/index.php/ambiencia/article/view/2841/0 doi: 10.5935/ambiencia.2015.02.08.

DAVIDE, A. C.; BOTELHO, S. A.; Fundamentos e métodos de restauração de ecossistemas florestais: 25 anos de experiências em matas ciliares. 1. ed. Lavras: Editora UFLA, 2015. v. 1. 636p.

FERREIRA, R. Q. S.; CAMARGO, M. O.; TEIXEIRA, P. R.; SOUZA, P. B.; VIANA, R. H.O.; Uso potencial e síndromes de dispersão das espécies de três áreas de cerrado sensu stricto, Tocantins. Global Science and Technology, Rio Verde, v.09, n.03, p.73 - 86, 2016. Disponível em: https://rv.ifgoiano. edu.br/ periodicos/index.php/gst/article/view/832/516

FINGER, Z.; FINGER, F. A.; Fitossociologia em comunidades arbóreas remanescentes de cerrado sensu stricto no brasil central. Floresta, v. 45, n. 4, p. 769-780, 2015. Disponível em: <http://dx.doi.org/10.5380/rf.v45i4.30860>. doi: 10.5380/rf.v45i4.30860.

GOULART, E. C.; RIBEIRO, M. C.; LIMA, L. M. DE; RODRIGUES, B. M. A. Uso de cama de aves na adubação da cultura do milho.; Enciclopédia Biosfera, Centro Científico Conhecer - Goiânia, v.11 n.22; p. 2015. Disponível em: http://www.conhecer.org.br/enciclop/2015c/agrarias/uso\%20de\%20cama\%20de $\% 20$ aves.pdf 
INM - Instituto Nacional de Meteorologia .; Banco de Dados Meteorológicos para Ensino e Pesquisa. (Jataí, GO). 2018. Disponível em: http://www.inmet.gov.br/portal/index.php?r=bdmep/bdmep.

JUSTINO, G, C.; OMENA-GARCIA, R. P.; SANTOS, A. M. S; CAMARGOS, L. S; SODEK, L. et al.; Nitrogen used strategies of nodulated amazonian legume: Inga edulis. Journal of Tropical Forest Science. v. 29, n. 1, p.1-9, 2017. Disponível em: http://www.jstor.org/stable/44028269.

LARA, R. O.; PEREIRA, I. M.; FERREIRA, E. A.; PEREIRA, G. A. M.; SILVA, D.V. et al.; Análise de cobertura, levantamento florístico e fitossiológico de uma área em recuperação com topsoil na Serra do Espinhaço, Brasil. Revista Espacios, v.38, n.39. p. 31-46. 2017. Disponível em: http://www.revistaespacios. com/a17v38n39/a17v38n39p31.pdf.

LIMA, P. A. F.; Crescimento de mudas de espécies nativas na restauração ecológica de matas ripárias. Neotropical Biology and Conservation, V. 11, №. 2, 2016, p. 72-79. Disponível em: http://revistas.unisinos.br/ index.php/neotropical/article/view/nbc.2016.112.03/5417 doi: 10.4013 /nbc. 2016. 112.03

MOREIRA, A. G. \& C. A. KLINK. 2000.; Biomass allocation and growth of tree seedlings from two contrasting Brazilian savannas. Ecotropicos, v. 13, n.1, p. 43-51, 2000. (Impresso)

OLIVEIRA, L. C. S.; GUIMARAES, J. C. O.; SOUZA, I. C. S.; LIMA, C. M.; FERREIRA, W.C.; Levantamento florístico e fitossociológico da regeneração natural de uma mata de galeria localizada no município de Jataí - GO. Global Science and Technology, v. 08, p. 59-77, 2015. Disponível em: https://rv.ifgoiano.edu.br/periodicos/index.php/gst/article/view/764. doi: http://dx.doi.org/10.14688/1984-3801/gst.v8n3p59-77

PAULILO, M. T. S. \& G. M. FELIPPE. Growth of the shrub-tree flora of the Brazilian cerrados: a review.; Tropical Ecology, v. 39, p.165-174, 1998. (Impresso)

PEREIRA, A. C.; SANTOS, E. R. Frutas nativas do Tocantins com potencial de aproveitamento econômico.; Agri-environmental sciences, Palmas, v. 1, n. 1, p. 22-37. 2015. Disponível em: https://revista.unitins.br/index.php/agri-environmentalsciences/article/view/44/120

RANGEL-VASCONCELOS, L. G. T.; KATO, O. R.; VASCONCELOS, S. S.; OLIVEIRA, F. A.; Acúmulo de biomassa e nutrientes de duas leguminosas arbóreas introduzidas em sistema de pousio na Amazônia. Ciência Florestal, Santa Maria, v. 26, n. 3, p. 735-746, set. 2016. Disponível em <http://www.scielo.br/ scielo.php? script=sci_arttext\&pid=S1980-50982016000300735\&Ing=pt\&nrm=iso>. acesso em 06 fev. 2018. http://dx.doi.org/10.5902/1980509824197.

REATTO, A.; CORREA, J.R; SPERA, S.T. Solos do cerrado: aspectos pedológicos. in: SANO,S.M.; ALMEIDA,S.P.; (Eds). Cerrado: ambiente e flora. Planaltina:EMBRAPA -CPAC, 2002. 
REIS, E. F.; NUNES, H.F.; PINTO, J.F.N.; Dissimilaridade Genética entre Genótipos de Guariroba Originados de Três Municípios do Estado de Goiás. Revista Agrotecnologia, v. 2, p. 1-13, 2011. Disponível em: http://www.prp.ueg.br/revista/index.php/agrotecnologia/index. doi: http://dx.doi.org/10.12971/2179-5959.v02n01a01

SCOPEL, I.; SILVA, M. R.; Erodibilidade no estado de Goiás. Uniciência, Anápolis, v. 8, n.1 e 2, p. 123-132, 2001.

SILVA, T. R.; MENEZES J. F. S.; SIMON, G. A.; ASSIS, L.A.; SANTOS, C. J. L.; GOMES, V.G.; Cultivo do milho e disponibilidade de $P$ sob adubação com cama de frango. Revista Brasileira de Engenharia Agrícola e Ambiental, v.15, n.9, p.903910, 2011. Disponível em: http://www.scielo.br/pdf/rbeaa/v15n9/05.pdf. doi: 10.1590/S1415-43662011000900005.

SILVA, A. J.; OLIVEIRA, V. H.; SANTOS, J. G.; SILVA, M. D. T.; SANTOS, T. E. B. et al.; Atributos biológico e físico-hídricos de um solo cultivado com eucalipto adubado com cama de frango em Mineiros-Go. Global Science and Technology, Rio Verde, v.08, n.03, p.12-20, set/dez. 2015. Disponível em: https://rv.ifgoiano.edu.br/periodicos/index.php/gst/article/view/740/478. doi: 10.14688 /1984-3801/gst.v8n3p12-20

TORRES, G. N.; VENDRUSCOLO, M. C.; SANTI, A.; SOARES, V. M.; PEREIRA, P. S. X.; Desenvolvimento de mudas de pinhão manso sob diferentes doses de cama de frango no substrato. Revista Verde, v. 6, n. 4, p. 244-250, Out./Dez., 2011. ISSN 1981-8203. Disponível em: http://gvaa.com.br/ revista/ index.php/RVADS/article/view/783/929

TROLEIS, M. J. B.; ROQUE, C. G.; BORGES, M. C. R.; NOGUEIRA, K. B.; GOUVEIA, N. A.; Estabilidade de agregados e teor de matéria orgânica em um Latossolo Vermelho sob Urochloa brizantha após a aplicação de cama de peru. Revista de Agricultura Neotropical, Cassilândia, MS, v. 4, n. 1, p. 83-87, jan./mar. 2017.

em:

https://periodicosonline.uems.br/index.php/agrineo/article/view/1267/1297. 